\title{
EFFECT OF YOGA ON BMI AND PFT AMONG PATIENTS WITH TYPE 2 DIABETES MELLITUS
}

\author{
Tyngshainlang Sutnga ${ }^{1}$, Sarada Ningthoujam², Franc Oumanath ${ }^{3}$ \\ 1Postgraduate Trainee, Department of Physiology, RIMS, Imphal, Manipur, India. \\ 2Professor, Department of Physiology, RIMS, Imphal, Manipur, India. \\ ${ }^{3}$ Tutor, Department of Physiology, SVMCHRC, Puducherry, India.
}

\section{BACKGROUND}

\section{ABSTRACT}

Yoga is considered to be a good exercise for maintaining proper health and also has a profound effect on the lung functions of an individual. Yogic practices help in prevention, control and rehabilitation of respiratory diseases associated with diabetes, and it also delays and prevent the complications of the disease.

Aims and Objectives- To assess the effect of yoga on BMI and pulmonary functions in type 2 diabetes mellitus patients.

\section{MATERIALS AND METHODS}

This non-randomized control trial was conducted at Department of Physiology and Department of Medicine in collaboration with Yoga Training and Research Centre, Kwakeithel, Imphal between January 2018 - June 2018, on 180 type 2 diabetes mellitus patients, classified into case $[\mathrm{n}=90]$ with yoga intervention and control $[\mathrm{n}=90]$ with no yoga. Baseline parameters, anthropometry and PFT, were recorded at the start and after 3 months. The sample size estimation was done at conveniences.

\section{RESULTS}

Results showed a significant difference in BMI between the groups and significant difference in pulmonary functions parameters like forced vital capacity (FVC), forced expiratory volume at 1st second (FEV1), peak expiratory flow rate (PEFR), and forced expiratory flow $\left(\mathrm{FEF}_{25 \%-75 \%}\right.$ ), at the end of 3 months, between the case group with yoga intervention and control group with no intervention.

\section{CONCLUSION}

Thus, three (3) months yoga training has been found to be effective in improving BMI and pulmonary functions of patients with type 2 diabetes mellitus, which can prevent the early onset of macrovascular and microvascular complications.

\section{KEY WORDS}

Yoga, BMI, Pulmonary Function Tests, Type 2 Diabetes Mellitus.

HOW TO CITE THIS ARTICLE: Sutnga T, Ningthoujam S, Oumanath F. Effect of yoga on BMI and PFT among patients with Type 2 diabetes mellitus. J. Evolution Med. Dent. Sci. 2019;8(05):329-332, DOI: 10.14260/jemds/2019/71

\section{BACKGROUND \\ Diabetes Mellitus is a public health problem in developing} and developed countries and according to World Health Organization (WHO) at least 366 million people worldwide have diabetes in 2011. This figure will rise to 552 million by 2030 and India will be the World Diabetic Capital by 2025.1,2

Diabetes mellitus is associated with widespread hormonal, metabolic, and microvascular abnormalities, as well as with disturbances of the function of many organ systems. The macroangiopathic and microangiopathic complications affect eyes, kidneys, nerves, cardiovascular system and respiratory system. The biochemical and structural change in basement membrane proteins of different body organ systems are the mainstay for development of diabetic complications. ${ }^{3}$ These alterations are reversible to start with, and can be delayed by keeping the blood sugar levels in the normal range. ${ }^{2}$

'Financial or Other Competing Interest': None.

Submission 14-11-2018, Peer Review 20-01-2019,

Acceptance 28-01-2019, Published 04-02-2019.

Corresponding Author:

Dr. Tyngshainlang Sutnga,

Postgraduate Trainee,

Department of Physiology,

RIMS, Imphal, Manipur, India.

E-mail: tyngshainlang1987@gmail.com sarada109@yahoo.com

DOI: $10.14260 /$ jemds $/ 2019 / 71$
However chronic hyperglycaemia causes non-enzymatic glycosylation of proteins such as collagen, elastin etc., which leads to thickening of basement membrane and microangiopathy. Microangiopathy in alveoli will restrict lung volumes and capacities. ${ }^{3}$

Yoga is a practical discipline incorporating a wide variety of practices whose goal is development of a state of mental and physical health and wellbeing. On the physical level, yoga asanas (Any posture which is steady and comfortable) are designed to tone, strengthen and align the body. These postures are performed to make the spine supple and healthy and to promote blood flow to all the organs, glands and tissue keeping all bodily systems healthy. ${ }^{4}$

Pranayama, the well-known yogic practice, has beneficial effects on respiratory efficiency. These exercises help to empty and fill the respiratory apparatus more completely and efficiently, leading to increased development of respiratory musculature and result in significant improvement in pulmonary parameters like forced vital capacity (FVC), forced expiratory volume in 1st second (FEV1) and peak expiratory flow rate (PEFR). 5,6

There has been intensive study from various parts of the World on yoga. But, there is paucity of data, especially in North-East India, relating the effect of yoga on BMI and pulmonary function test in patients with type 2 diabetes mellitus. Therefore, the present study is undertaken to assess the effect of yoga on BMI and pulmonary functions type 2 diabetes mellitus. 


\section{MATERIALS AND METHODS}

This non-randomized control trial was conducted in the department of Physiology and department of Medicine, Regional Institute of Medical Sciences (RIMS), Imphal, in collaboration with Yoga Training and Research Centre (YTRC) bearing registration no. 38 of 1987 Kwakeithel.

A total of 180 participants, age group 30 to 75 years, diagnosed with type 2 diabetes mellitus were recruited based on the following criteria: The sample size estimation was also done at conveniences.

\section{Inclusion Criteria}

1. Type 2 diabetes mellitus patients newly enrolled at YTRC, Kwakeithel between the age group $30-75$ years, irrespective of sex.

2. Type 2 diabetes mellitus patients attending Medicine department, RIMS, Imphal between the age group 30 75 years, irrespective of sex.

\section{Exclusion Criteria}

1. Those who did not want to participate

2. Patients who did not come for subsequent visits

3. Patients with past history of Yoga training

4. Athletes or Patients undergoing any other form of physical exercises

5. Patients with history of chronic illness like uncontrolled hypertension, angina, stroke, renal failure, COPD, tuberculosis, coronary artery disease and musculoskeletal chest deformity.

Yoga intervention [asanas, pranayama and meditation] were given for a duration of three (3) months, at YTRC, Kwakeithel, in the case group. Anthropometric measurement and pulmonary function tests were carried out in the department of Physiology, RIMS, Imphal, before the start of yoga and following three (3) months of yoga training in the case group. Pulmonary function tests were also recorded for the control group at start of the study and at the end of the 3rd month, but with no yoga intervention. Pulmonary function tests were recorded using a computerized spirometer: Helios 401/701 of the Recorders and Medicare System, Chandigarh.

The study was carried out after obtaining clearance from the Research Ethics Board (REB), RIMS, Imphal. Written informed consent was taken from each participant. Privacy and confidentiality were maintained through-out the study by limiting the identifying variables to the minimum and by using unique identification number. Data collected were not linked to identify the individual in any way or data collection process did not harm the participants in any way.

\section{Statistical Analysis}

Data were entered and analysed using IBM SPSS statistics version 21 for windows. Paired ' $t$ ', unpaired ' $t$ ' test were done for comparison of means before and after 3 months. A p $<0.05$ was taken as significant.
RESULTS
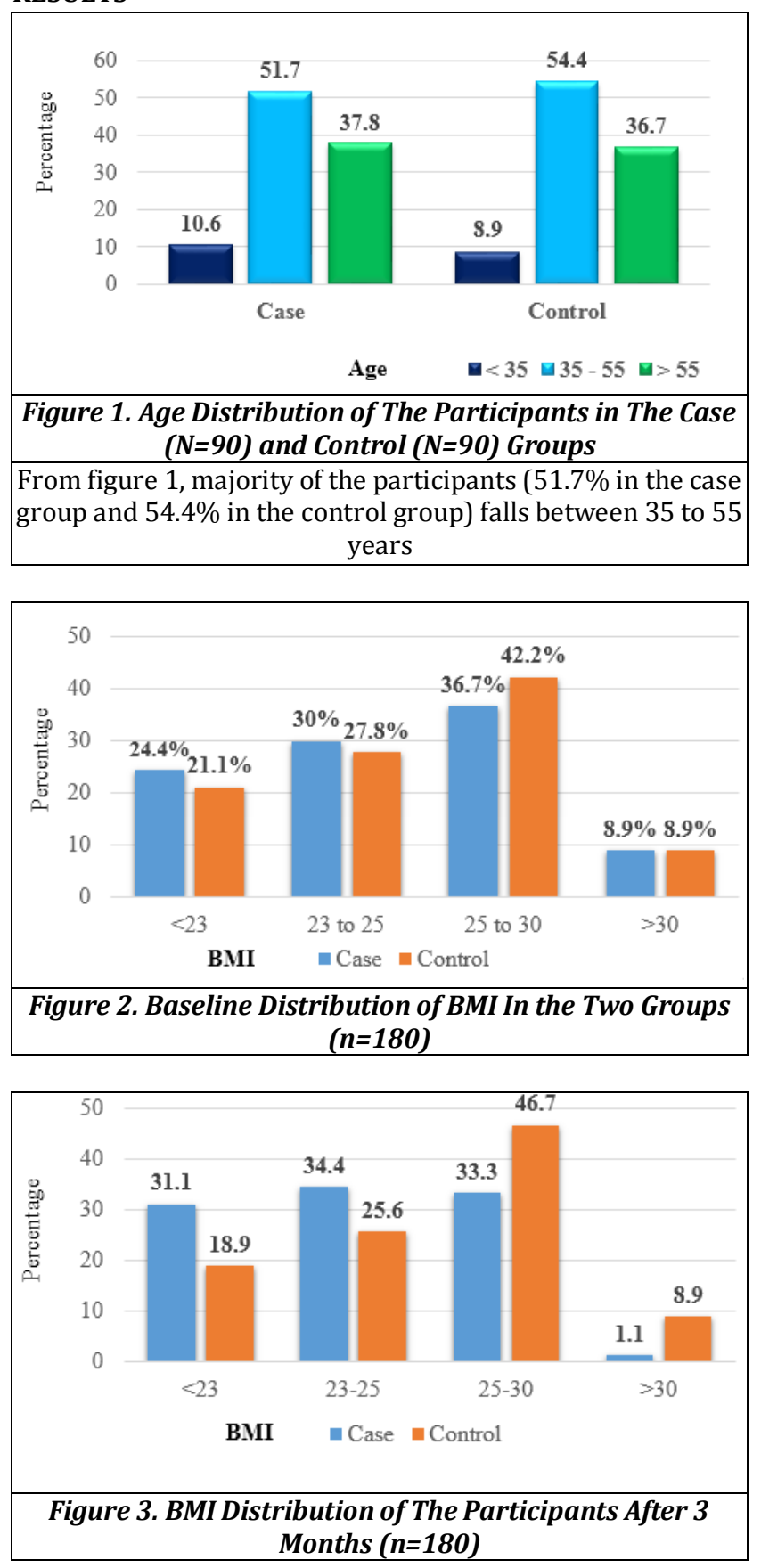

\begin{tabular}{|c|c|c|c|}
\hline BMI & Case [n=90] & Control [n=90] & p-value \\
\hline$<23$ & $20.69 \pm 1.41$ & $25.47 \pm 3.23$ & 0.002 \\
$23-25$ & $24.23 \pm 0.62$ & $24.58 \pm 3.05$ & 0.018 \\
$25-30$ & $26.70 \pm 1.30$ & $25.87 \pm 2.71$ & 0.015 \\
$>30$ & $23.69 \pm 0.57$ & $23.94 \pm 3.42$ & 0.004 \\
\hline
\end{tabular}

Table 1. Baseline Mean BMI of The Participants in The Two Groups

\begin{tabular}{|c|c|c|c|}
\hline BMI & Case [n=90] & Control [n=90] & p-value \\
\hline$<23$ & $20.24 \pm 1.29$ & $25.73 \pm 3.21$ & 0.001 \\
$23-25$ & $23.60 \pm 0.55$ & $24.84 \pm 3.11$ & 0.013 \\
$25-30$ & $26.11 \pm 1.39$ & $26.06 \pm 2.69$ & 0.003 \\
$>30$ & $22.64 \pm 2.65$ & $24.29 \pm 3.65$ & 0.016 \\
\hline
\end{tabular}

Table 2. Mean BMI of The Participants in The Two Groups, After 3 Months 


\begin{tabular}{|c|c|c|c|}
\hline \multirow{2}{*}{ Parameters } & \multicolumn{3}{|c|}{ Baseline Pulmonary function tests } \\
\cline { 2 - 4 } & Case [n=90] & Control [n=90] & p-value \\
\hline FVC & $2.54 \pm 0.70$ & $2.54 \pm 0.67$ & 0.944 \\
\hline FEV1 & $1.62 \pm 0.56$ & $1.68 \pm 0.55$ & 0.292 \\
\hline FEV1/FVC & $64.65 \pm 13.60$ & $65.99 \pm 12.91$ & 0.498 \\
\hline FEF $25 \%-75 \%$ & $1.40 \pm 0.67$ & $1.51 \pm 0.69$ & 0.267 \\
\hline PEFR & $2.69 \pm 1.51$ & $2.42 \pm 5.45$ & 0.222 \\
\hline MVV & $60.87 \pm 29.15$ & $66.45 \pm 29.68$ & 0.204 \\
\hline
\end{tabular}

Table 3. Baseline-Mean Pulmonary Function Tests Profile of The Case and Control Group

From table 3, there was an insignificant difference between the mean parameters when comparing between the two groups at the beginning of the study

\begin{tabular}{|c|c|c|c|}
\hline \multirow{2}{*}{ Parameters } & \multicolumn{3}{|c|}{ Pulmonary function tests after 3 months } \\
\cline { 2 - 4 } & Case [n=90] & Control [n=90] & p-value \\
\hline FVC & $2.73 \pm 0.71$ & $2.53 \pm 0.67$ & 0.024 \\
\hline FEV1 & $1.85 \pm 0.57$ & $1.67 \pm 0.56$ & 0.018 \\
\hline FEV1/FVC & $64.09 \pm 13.69$ & $65.15 \pm 13.18$ & 0.001 \\
\hline FEF $_{25 \%-75 \%}$ & $1.67 \pm 0.68$ & $1.45 \pm 0.68$ & 0.014 \\
\hline PEFR & $2.95 \pm 1.52$ & $2.77 \pm 1.50$ & 0.002 \\
\hline MVV & $67.34 \pm 28.84$ & $64.53 \pm 29.29$ & 0.004 \\
\hline \multicolumn{4}{|c|}{ Table 4. Mean Pulmonary Function Tests Profile of The } \\
Case and Control Groups After 3 Months
\end{tabular}

Following 3 months, there was a significant difference in FVC, FEV1, FEF25-75\% and PEFR on comparing the mean between the case and control groups, as shown in table 4

\section{DISCUSSION}

In our study, $72.2 \%$ in the case and $70 \%$ in the control were females with a mean age of $51.52 \pm 12.49$ and $51.89 \pm 11.66$ years respectively (Figure 1). This is due to the fact that the incidence of diabetes increases with increasing age due to physical inactivity and sedentary life style.4,5

Figure 2 and figure 3 shows the percentage distribution of the BMI of the case and control group at the beginning of the study and after 3 months respectively. The mean BMI of the two groups, at baseline shows no significant difference [Table $1, \mathrm{p}=0.422]$. However, at the end of three months, the mean BMI of the case group shows a decrease in all the categories of BMI and increases in the control group: the value of which is significant [Table 2, $\mathrm{p}=0.004]$. Parthiban et al7 also reported that suryanamaskar with pranayama, suryanamaskar with meditation practice group shows a significantly decreased in BMI. Similar study of Herur et al ${ }^{8}$ reported a significant better response in subjects with BMI of $>25$ to 6 months yoga training. Moliver et $\mathrm{al}^{9}$ does report a significant difference in BMI between yoga practitioners and non-practitioners, and that participants who practiced yoga were on average of normal weight, and participants who did not practice yoga were on average close to the level of obesity.

Following 3 (Three) months of yoga training, there was a significant difference in pulmonary functions between the case and control group. Our study showed a statistically significant difference in FVC, $\mathrm{p}=0.024$ (Case-2.73 \pm 0.71 ; control-2.53 \pm 0.67): FEV1, $\mathrm{p}=0.018$ (Case-1.85 \pm 0.57; control-1.67 \pm 0.56): FEF25\%-75\%, p=0.014 (Case1.67 \pm 0.68 ; control-1.45 \pm 0.68 ): and PEFR, $p=0.002$ (Case$2.95 \pm 1.52$, control $-2.77 \pm 1.50$ ). However, there was a nonsignificant difference in FEV1/FVC $(p=0.001)$ and MVV $(p=0.004)$ between the two groups (Table 4$)$.
Ahmed et $\mathrm{al}^{10}$ also reported a significant increase in FVC, FEF, MVV among the older group age between 41 to 50 years (In 30 days yoga). Malhotra et $\mathrm{al}^{11}$ reported increase in FVC, significant increase in FEV1 and PEFR among the diabetic patients after yoga training. Makwana et al 12 also reported significant increase in FVC following 10 weeks of yoga training. This is the evidence that yoga has a positive effect on the FVC in the young healthy subjects, older adults, elderly and even among the diabetic persons whose vital capacity have reduced because of tissue changes induced by high blood glucose level.

Malhotra et al ${ }^{11}$ also reported an insignificant improvement in FEV1/FVC after 40 days of yoga, a finding similar to our study, but other study of Ahmed et al10 has reported a significant increase in FEV1/FVC in 30 day and 60 days yoga training.

\section{CONCLUSION}

Three (3) months yoga training brings a positive improvement in BMI and is effective in improving the pulmonary functions of patients with type 2 diabetes mellitus, which can prevent the early onset of macrovascular and microvascular complications. Thus, yoga training can be added to the treatment regime of type 2 diabetes mellitus patients, and they can be educated on the positive effects of yoga knowledge and techniques on physical, mental and emotional health.

\section{REFERENCES}

[1] Dash S, Thakur AK. Effect of yoga in patients with type-II diabetes mellitus. J Evol Med Dent Sci 2014;3(7):1642-55.

[2] Verma S, Goni M, Kudyar RP. Assessment of pulmonary functions in patients with diabetes mellitus. JK Sci 2009;11(2):71-4.

[3] Yadav A, Saxena AK, Gaur K, et al. Study of pulmonary function tests in type 2 diabetes mellitus: case control study. J Dent Med Sci 2013;10(5):74-7.

[4] Ahmed AM. History of diabetes mellitus. Saudi Med J 2002;23(4):373-8.

[5] Chakraborty T, Das K, Samajdar K. Effect of yogic exercise on selected pulmonary function tests in apparently healthy elderly subjects. J Dent Med Sci 2013;9(1):1-5.

[6] Shaikh GB, Deshpande AA, Kanthe PS, et al. A comparative study of lung functions in type 2 diabetes and non-diabetic subjects. Inter J Biomed Adv Res 2012;3(8):629-31.

[7] Parthiban V, Vallimurugan V. Effects of variation of yogic practices on BMI and flexibility among obese college men. Int J Appl Res 2016;2(7):391-3.

[8] Herur A, Kolagi S, Chinagudi S. Effect of body mass index and gender on the cardiovascular and mental response to yoga. Biomedical Research 2011;22(4):499-505.

[9] Moliver N, Mika E, Chartrand M, et al. Increased Hatha yoga experience predicts lower body mass index and reduced medication use in women over 45 years. Int J Yoga 2011;4(2):77-86. 
[10] Ahmed QR, Sau SK, Kar SK. An evaluation of pulmonary parameters in two groups of subjects during Yoga practice. Nepal Med Coll J 2010;12(3):180-2.

[11] Malhotra V, Singh S, Singh KP, et al. Study of Yoga asanās in assessment of pulmonary function in NIDDM patients. Indian J Physiol Pharmacol 2002;46(3):31320.
[12] Makwana K, Khirwadkar B, Gupta HC. Effect of short term yoga practice on ventilatory function tests. Indian J Physiol Pharmacol 1988;32(3):202-8. 